\title{
Preparation and characterization of nanocomposite uralkyd varnishes for a wood substrate
}

\author{
Krzysztof Kowalczyk
}

(C) The Author(s) 2014. This article is published with open access at Springerlink.com

\begin{abstract}
Three types of commercially modified montmorillonites (mMMT) have been tested as nanofillers in solventborne uralkyd coating compositions. The mMMT was introduced in the amount of $0.5 \mathrm{wt}$ part into a coating system based on a soya oil fatty acid and isophorone diisocyanate (100 wt parts), applied onto a wood substrate, and oxidatively cured at room temperature for 14 days. An incorporation of organophilized montmorillonite into a coating composition significantly affects its viscosity (mMMT with a higher gallery space value increases that parameter) and slightly reduces the hardness of a dry coat. Moreover, a clay nanofiller increases glass transition temperature, abrasion resistance, elasticity, and impact resistance as well as barrier properties (measured using a conventional gravimetric method and an electrochemical impedance spectroscopic test) of a cured varnish. In the case of chemical resistance to acetone, lower blistering of modified coats was found.
\end{abstract}

Keywords EIS, Montmorillonite, Nanocomposite, Uralkyd, Wood varnish

\section{Introduction}

Modified montmorillonites (mMMT) are widely used as nanofillers in casting and extruded polymeric materials and significantly enhance their mechanical properties, thermal stability, fire resistance as well as barrier features. $^{1-3}$ Moreover, organoclays are incorporated

K. Kowalczyk $(\square)$

Polymer Institute, West Pomeranian University

of Technology in Szczecin, ul. Pułaskiego 10,

70-322 Szczecin, Poland

e-mail: kkowalczyk@zut.edu.pl into powder, solventborne, and water-thinnable coating compositions containing polyurethanes as well as epoxy, acrylic, and alkyd resins. Nanoclay can be introduced into a solid or liquid coating composition by (i) homogenization with a melted binder, e.g., in an extruder, (ii) premixing (and swelling occasionally) with monomer or liquid resin, and (iii) milling and/or high-speed mixing with a binder containing solvent or water. ${ }^{40}$ In many cases improved hardness, adhesion, gloss retention, and abrasion resistance of modified coats on a steel substrate have been observed. Additionally, protective acrylic and epoxy coating compositions with organophilized montmorillonites have been successfully tested on a concrete substrate. These polymeric systems significantly upgrade moisture penetration resistance of the aforementioned material. ${ }^{11,12}$ Although there are a few scientific contributions about aluminosilicate in acrylic varnishes used for wood protection, $^{13,14}$ this reinforcing nanofiller has not yet been circumstantially tested as a component of coating compositions based on vegetable oil. Alkyds and uralkyds prepared by using drying and/or nondrying oils are commonly offered on the market as DIY-type ("Do It Yourself") varnishes and paints designed for application onto various wooden elements such as doors, window frames and sills, wainscots, handholds, and furniture. Moreover, uralkyds (mainly based on aliphatic isocyanates) are used for protecting the exterior elements due to their high hydrolytic resistance. Decorative, mechanical, and barrier properties of these compositions are generally worse in comparison with either acrylic or polyurethane systems; nevertheless, alkyds and uralkyds (mainly as solventborne products) are very popular due to their affordable price and easy application.

This work focuses on the application and protective features of an uralkyd coating system modified with organophilized montmorillonites with different organic modifiers and gallery spaces. Rheological, mechanical, 
and protective properties of prepared solventborne varnishes and oxidatively cured coats on a wood substrate have been evaluated. Generally, barrier characteristics of the mentioned materials were investigated using an electrochemical impedance spectroscopy. In the author's opinion, this technique has never been applied to wooden elements protected with an organic varnish modified with a nanofiller.

\section{Materials and methods}

\section{Materials}

Solventborne uralkyd varnishes were prepared using the following commercial components:

- WorléeKyd S5703, 55\% solution in white spirit of a long oil-type uralkyd resin based on soya oil fatty acid and isophorone diisocyanate, viscosity ca. $6000 \mathrm{mPa} . \mathrm{s}$ at $20^{\circ} \mathrm{C}$ (Worlée-Chemie $\mathrm{GmbH}$, Germany);

- Octa-Soligen Calcium 10 (OS-Ca), siccative based on the calcium salt of 2-ethylhexanoic acid (OMG Borchers GmbH, Germany);

- Octa-Soligen Cobalt 12 (OS-Co), the cobalt salt of 2-ethylhexanoic acid (OMG Borchers);

- Octa-Soligen Zirconium 18 (OS-Zr), the zirconium salt of 2-ethylhexanoic acid (OMG Borchers);

- BorchiNox 55 (BN55); an antiskinning agent, 55\% solution of a synthetic proprietary product in white spirit (OMG Borchers);

- White spirit (Dragon, Poland).

Three Polish organophilic-modified montmorillonites as nanofillers have been applied:

- NanoBent ZS1 (ZS1), pulverized montmorillonite modified with the ammonium salt bearing long-chain aliphatic and aromatic substituents with several hydroxyl groups, powder with particle diameter $\leq 63 \mu \mathrm{m}$, gallery space $3.5 \mathrm{~nm}$ and modifier content ca. $42 \mathrm{wt} \%$ (Z.G.M. Zebiec S.A., Starachowice, Poland);

- NanoBent ZS3 (ZS3), pulverized montmorillonite modified with the ammonium salt bearing long-chain aliphatic substituents with several hydroxyl groups and etheric bonds, powder with particle diameter $\leq 63 \mu \mathrm{m}$, gallery space $3.7 \mathrm{~nm}$ and modifier content ca. $48 \mathrm{wt} \%$ (Z.G.M. Zebiec S.A.);

- NanoBent ZR2 (ZR2), pulverized montmorillonite modified with the ammonium salt bearing long-chain aliphatic substituents, powder with particle diameter $\leq 63 \mu \mathrm{m}$, gallery space $1.9 \mathrm{~nm}$ and modifier content ca. 30 wt\% (Z.G.M. Zebiec S.A.).

\section{Varnishes preparation}

\section{Unfilled varnish}

WorléeKyd S5703, white spirit, and calcium siccative (0.2 wt part of metal/100 wt parts of uralkyd resin) were mixed using a laboratory dissolver with a heavyduty dispersion impeller (VMA Getzmann GmbH, Germany) at $400 \mathrm{rpm}$ for $30 \mathrm{~min}$. Then cobalt siccative (0.05 wt part of metal), zirconium siccative (0.08 wt part of metal/100 wt parts of uralkyd resin) and an antiskinning agent $(0.4 \mathrm{wt}$ part/100 wt parts of WorléeKyd S5703 and siccatives mixture) were added and this composition was agitated for $10 \mathrm{~min}$.

\section{Varnish with organophilized montmorillonites}

WorléeKyd S5703, white spirit, nanofiller dispersion (i.e., $20 \mathrm{wt} \%$ of mMMT in WorléeKyd S5703) and calcium siccative were mixed using a laboratory dissolver with a heavy-duty dispersion impeller (VMA Getzmann) at $1200 \mathrm{rpm}$ for $30 \mathrm{~min}$. Calcium siccative doses depended on a nanofiller type and reached 0.213 wt part (sample with ZS1), 0.21 wt part (ZS3), and $0.215 \mathrm{wt}$ part of metal/100 wt parts of the uralkyd resin (ZR2). The amount of mentioned siccative was calculated on the basis of montmorillonite content in a nanofiller and assumed cation exchange capacity (CEC) value for clays, i.e., $100 \mathrm{mmol} / 100 \mathrm{~g}$ of MMT. Then cobalt siccative (0.05 wt part of metal), zirconium siccative $(0.08 \mathrm{wt}$ part of metal/100 wt parts of uralkyd resin), and an antiskinning agent (0.4 wt part/100 wt parts of WorléeKyd S5703 and siccatives mixture) were added and this composition was agitated at $400 \mathrm{rpm}$ for $10 \mathrm{~min}$. Prepared varnishes contained $0.5 \mathrm{wt}$ part of a modified montmorillonite/100 wt parts of WorléeKyd S5703 solid content. The varnishes recipe is specified in Table 1.

\section{Samples preparation}

Spruce (Picea abies) boards were ground with the P-220 type abrasive paper, band-sawed for samples without knots $(75 \mathrm{~mm} \times 70 \mathrm{~mm} \times 20 \mathrm{~mm}$ for elasticity and gloss tests, $80 \mathrm{~mm} \times 80 \mathrm{~mm} \times 20 \mathrm{~mm}$ for chemical resistance tests and electrochemical measurements, $140 \mathrm{~mm} \times 150 \mathrm{~mm} \times 20 \mathrm{~mm}$ for impact resistance tests and $160 \mathrm{~mm} \times 70 \mathrm{~mm} \times 20 \mathrm{~mm}$ for water permeation tests), dedusted and conditioned at $23^{\circ} \mathrm{C}$ $(65 \% \mathrm{RH})$ for 7 days. Blind holes $(\varnothing 8 \mathrm{~mm})$ were made in the samples (for electrochemical impedance spectroscopic tests) before their coating.

Pendulum hardness was determined using glass plates $(100 \mathrm{~mm} \times 100 \mathrm{~mm} \times 4 \mathrm{~mm})$. Samples for the abrasion test were prepared using steel plates (Q-Panels, $152 \mathrm{~mm} \times 102 \mathrm{~mm}$ ) supplied by Q-Lab Europe 
Table 1: Composition of uralkyd varnishes and glass transition temperature of cured uralkyd coats

\begin{tabular}{|c|c|c|c|c|c|c|c|c|c|}
\hline \multirow{2}{*}{$\begin{array}{l}\text { Varnish } \\
\text { acronym }\end{array}$} & \multirow[t]{2}{*}{ W'Kyd S5703 (g) } & \multirow{2}{*}{$\begin{array}{l}\text { mMMT } \\
\text { type }\end{array}$} & \multirow{2}{*}{$\begin{array}{c}\text { mMMT } \\
\text { dose (g) }\end{array}$} & \multicolumn{3}{|c|}{ Siccatives (g) } & \multirow[t]{2}{*}{ BN55 (g) } & \multirow{2}{*}{$\begin{array}{l}\text { White } \\
\text { spirit (g) }\end{array}$} & \multirow[t]{2}{*}{$T_{\mathrm{g}}^{\mathrm{b}}\left({ }^{\circ} \mathrm{C}\right)$} \\
\hline & & & & $\overline{\mathrm{OS}-\mathrm{Ca}}$ & OS-Co & OS-Zr & & & \\
\hline WK & 80 & - & 0 & 0.88 & 0.183 & 0.196 & 0.325 & 5 & 24.5 \\
\hline WK/ZS1 & 79.12 & ZS1 & $1.1^{\mathrm{a}}$ & 0.935 & 0.183 & 0.196 & 0.325 & 5 & 24.7 \\
\hline WK/ZS3 & 79.12 & ZS3 & $1.1^{\mathrm{a}}$ & 0.923 & 0.183 & 0.196 & 0.325 & 5 & 28.1 \\
\hline WK/ZR2 & 79.12 & ZR2 & $1.1^{\mathrm{a}}$ & 0.944 & 0.183 & 0.196 & 0.325 & 5 & 25.6 \\
\hline
\end{tabular}

a 20 wt\% dispersion of mMMT in WorléeKyd S5703

b Glass transition temperature for cured coats

(Bolton, England). Glass transition temperature values of varnishes were measured using samples cured on a PET substrate.

Spruce samples were preliminarily primed with a tested varnish containing $40 \mathrm{wt} \%$ of solids using a brush (according to the Polish Standard PN-C81514:1979) and dried for $48 \mathrm{~h}$ at room temperature. The next two layers of an undiluted varnish (45 wt \% of solids) were applied onto slightly ground coated samples (using the P-220 abrasive paper) with $48 \mathrm{~h}$ applying intervals. Glass plates (for hardness test), PET foil (for $T_{\mathrm{g}}$ analysis of uralkyd layer) as well as a steel substrate (for an abrasion resistance test) were coated using gap applicators $(120,120$, and $60 \mu \mathrm{m}$, respectively).

\section{Test methods}

Viscosity tests at $1,2.5,5,10,20,50$, and $100 \mathrm{rpm}$ of a spindle were performed on ready-to-use ( $45 \mathrm{wt} \%$ of solids) liquid coating compositions (Brookfield RV viscometer, Brookfield Eng. Lab., USA). X-ray diffraction patterns for cured uralkyd varnishes were obtained with the X'Pert PRO Philips diffraction meter $(\mathrm{Cu} \mathrm{K} \alpha$, $0^{\circ}-14^{\circ} 2 \theta$ ) using the X'Pert PRO High Score Philips software. Pendulum hardness was evaluated according to the Polish standard PN-EN ISO 1522:2008 (König pendulum, three measurements for each system); daily pendulum hardness tests were made for 14 days after varnish application. Gloss value at $60^{\circ}$ (six measurements; ISO 2813, Micro-TRI-gloss $\mu$, BYK-Gardner $\mathrm{GmbH}$, Germany), elasticity and impact resistance (three measurements; PN-EN 13696:2009), abrasion resistance (four measurements; PN-C-81516:1976, falling sand abrasion method), chemical resistance (three samples; PN-EN 13442:2004) as well as water permeability (three samples; PN-EN 927-5:2008) were evaluated on coated samples conditioned for 14 days at RT. Thickness of cured films (on a steel substrate) was measured with the electronic film gage Byko-test 8500 (BYK-Gardner GmbH, Germany) according to PN-EN ISO 2808.

Glass transition temperature of cured varnishes as the temperature of tan delta peak was evaluated using

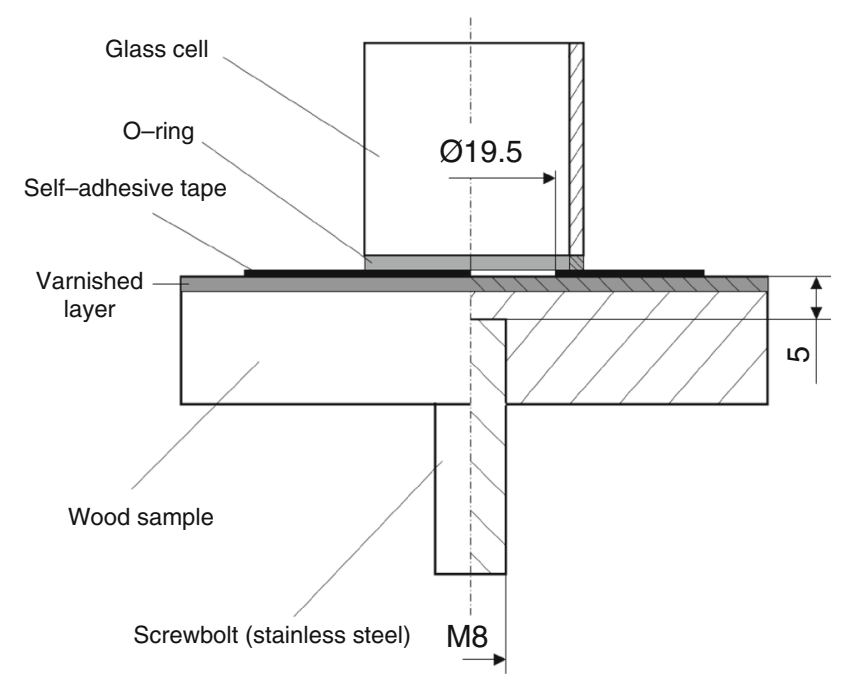

Fig. 1: Scheme of a varnished wood sample with a central working electrode for EIS test

a dynamic mechanical analyzer Q800 (tension test in a range -10 to $125^{\circ} \mathrm{C}$, heating rate $3^{\circ} \mathrm{C} / \mathrm{min}, 1 \mathrm{~Hz}$ frequency, amplitude $15 \mu \mathrm{m}$; TA Instruments, USA).

Chemical resistance of a cured varnish was evaluated by a visual observation of the sample after treating with acetone for $4 \mathrm{~h}, 10 \mathrm{wt} \%$ aqueous solution of ammonia ( $8 \mathrm{~h}$ ) or $10 \mathrm{wt} \%$ aqueous solution of acetic acid $(24 \mathrm{~h})$. Chemicals were applied onto tested surfaces using a blotting-paper.

Water permeability tests were realized using varnished samples with edges and a back side coated with a commercial polyvinyl paint. Weighed samples were carefully placed (varnished side down) onto a surface of distilled water and left for $24 \mathrm{~h}, 72 \mathrm{~h}$, and 7 days at RT. Then, the samples were quickly dried with a blotting-paper, weighed, and a water permeability value (WP) was calculated according to the following equation:

$\mathrm{WP}=\left(m_{2}-m_{1}\right) / A\left[g / m^{2}\right]$,

where $m_{1}$ is the mass of a sample (before testing), $m_{2}$ is the mass of a water-treated sample, $A$ is the area of a tested varnished surface. 
EIS tests were carried out with the samples (unvarnished or coated) after their vacuum impregnation with an aqueous $\mathrm{NaCl}$ solution (3.5 wt\%) and additionally after 3 days of their immersion in the mentioned saline. These measurements were realized using three coated samples for each tested composition. A glass cell (with $3 \mathrm{~cm}^{2}$ surface sample area) equipped with a graphite counter electrode and a saturated calomel reference electrode was used inside the Faraday cage. Stainless bolt (M8) was screwed into the sample before the test and used as a working electrode (Fig. 1). The impedance data (at frequency 0.003$10,000 \mathrm{~Hz}, 20 \mathrm{mV}$ amplitude of sinusoidal voltage vs open circuit potential) was collected using the EIS300 software with the FAS2 femtostat (Gamry, USA) and analyzed with three electric circuit models presented in Fig. $2 \quad\left(R_{\mathrm{u}}\right.$-uncompensated solution resistance, $R_{\mathrm{v}}$-varnished layer resistance, $C_{\mathrm{v}}$-varnished layer capacitance, $R_{\mathrm{w}}$-wood substrate resistance, $C_{\mathrm{w}}$-wood substrate capacitance, $R$-sample resistance, $R_{\mathrm{i}}$ and $C_{\mathrm{i}}$-resistance and capacitance of wood/bolt interlayer, respectively). In the case of a standard electric model (Fig. 2b) varnished layer resistance and capacitance were measured using $R_{\mathrm{w}}$,
$C_{\mathrm{w}}, R_{\mathrm{i}}$, and $C_{\mathrm{i}}$ values determined for unvarnished samples using a reference electric model (Fig. 2a). The data for all electric components presented in a reduced electric model (Fig. 2c) was automatically computed by the EIS300 software. Resistance and capacitance of a varnished layer were calculated in respect to $1 \mathrm{~cm}^{2}$ of a sample and presented as a relative $R_{\mathrm{v}}$ (i.e., $R_{\mathrm{vr}}$, $\left.\Omega . \mathrm{cm}^{2}\right)$ and a relative $C_{\mathrm{v}}\left(C_{\mathrm{vr}}\right.$, F.cm $\left.{ }^{-2}\right)$ with a standard deviation.

\section{Results and discussion}

The viscosity curves for a liquid unmodified uralkyd varnish as well as varnishes containing organophilized montmorillonites are presented in Fig. 3. As can be seen the coating composition with either ZR2 or ZS1 (at rotation speed $>10 \mathrm{rpm}$ ) reached lower viscosity than a neat system. On the other hand, varnish filled with ZS3 exhibited higher value of an analyzed parameter at the applied rotation speed (1-100 rpm) in comparison with an unmodified coating composition. Moreover, it should be noted that the strongest
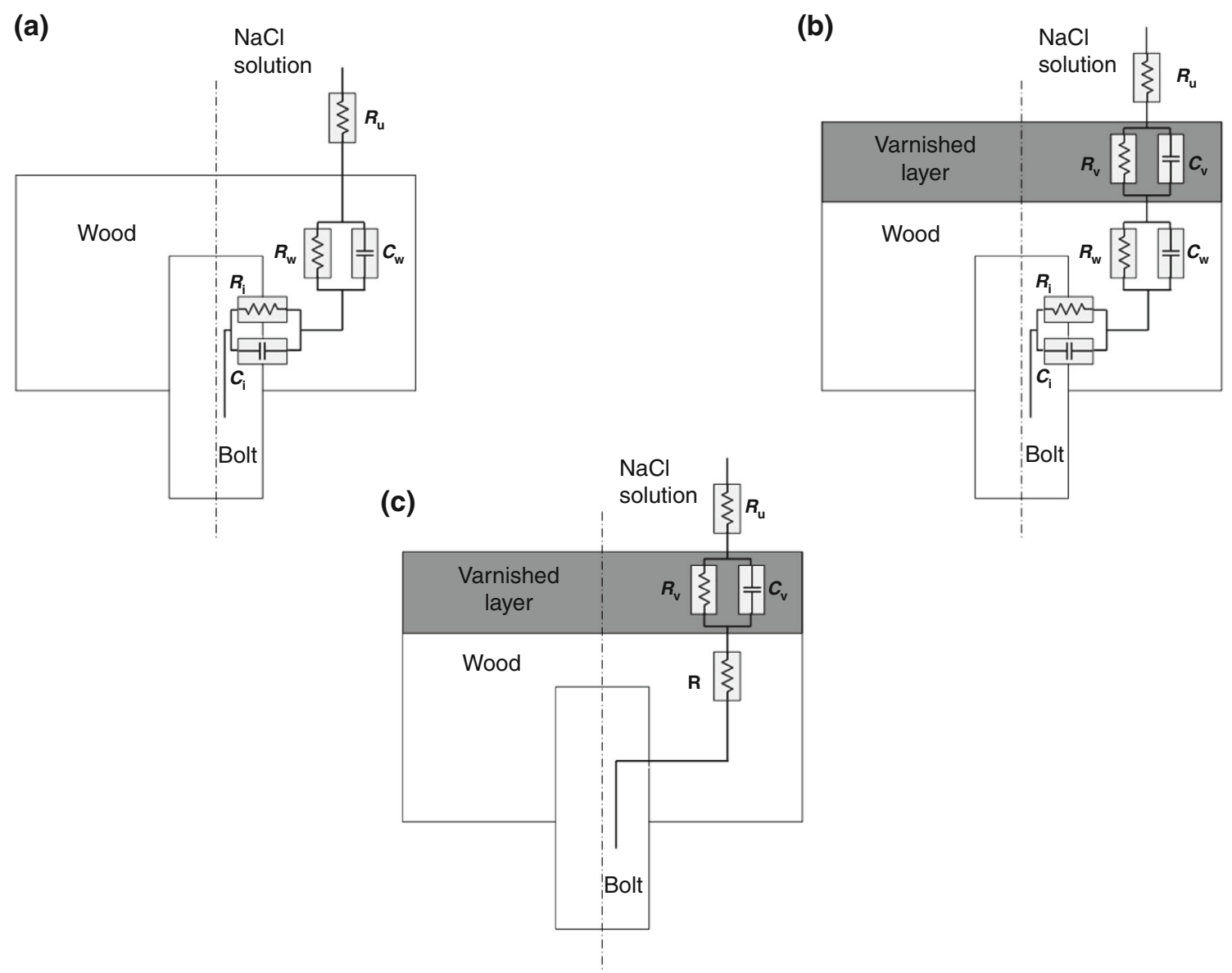

Fig. 2: Localization of electric circuit model elements in: (a) an unvarnished wood sample, (b) a varnished wood sample, and (c) a varnished wood sample (reduced electric model) 


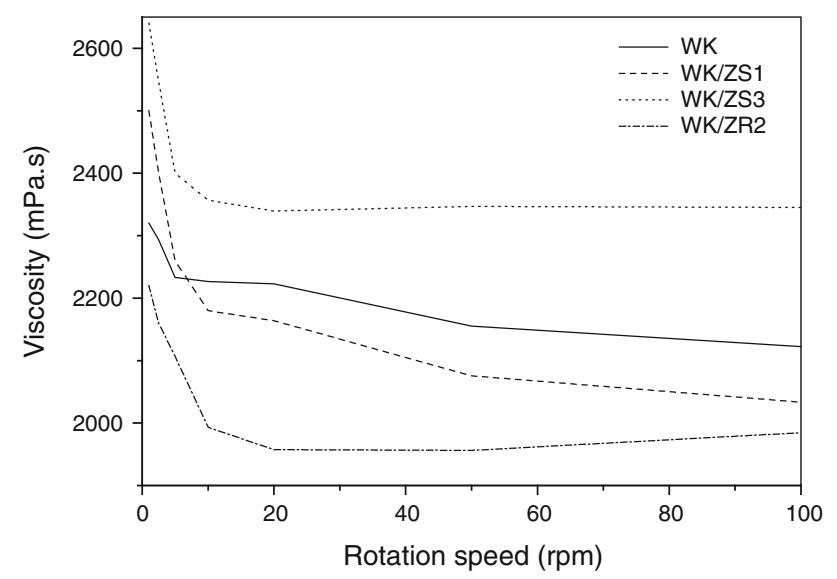

Fig. 3: Viscosity of liquid uralkyd varnishes with organophilized montmorillonites

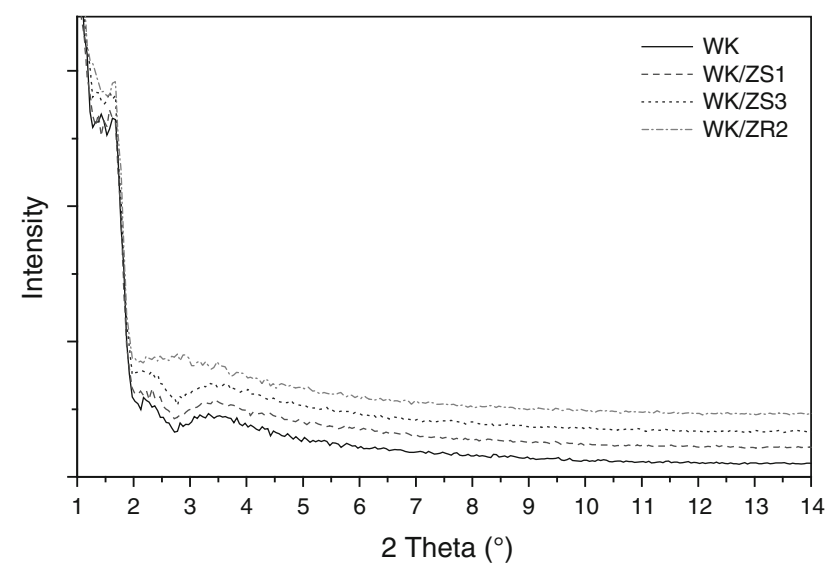

Fig. 4: XRD curves of uralkyd coats with organophilized montmorillonites

pseudoplasticity for the WK/ZS1 was observed-viscosity for that composition (at rotation speed $\leq 10 \mathrm{rpm}$ ) is higher than for WK while its values for WK/ZS1 and WK/ZR2 are quite similar at $100 \mathrm{rpm}$. Interestingly, viscosity of uralkyd with mMMT generally correlates with a gallery space value of an incorporated nanofiller; ZS3 was characterized by $3.7 \mathrm{~nm}$ (varnish with the highest viscosity) whereas ZR2 reached only $1.9 \mathrm{~nm}$ (the lowest viscosity). Taking into consideration the XRD curves for uralkyd coats (Fig. 4), it can be seen that these for a WK sample and coats with either ZS1 or ZS3 are similar and extra peaks (for coats with mentioned mMMTs) were not registered. It shows that ZS-type nanofillers were fully exfoliated in a polymeric matrix. In the case of WK/ZR2 coats an additional peak at $2.9^{\circ} 2 \theta(\sim 3.1 \mathrm{~nm})$ for intercalated mMMT platelets was observed.

Pendulum hardness test results for uralkyd coats are presented in Fig. 5. The lowest value of that feature after 14 days of curing at RT (i.e., 32 units) for the

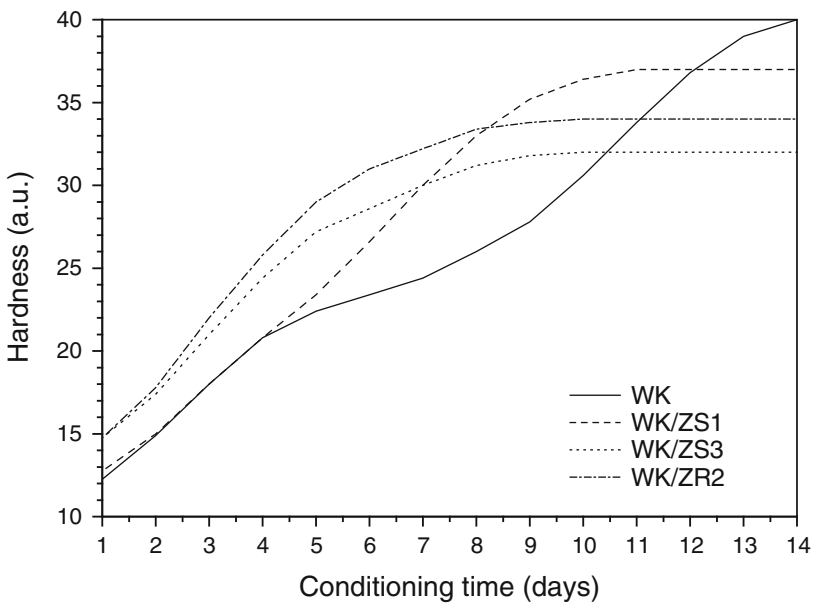

Fig. 5: Hardness variation during conditioning (at RT) of uralkyd coats with organophilized montmorillonites

sample filled with ZS3 was observed. Although cured WK varnish reached the highest hardness (40 units after 14 days), this composition as well as a system based on ZS1 had achieved significantly low initial values of the analyzed parameter (i.e., 12-13 units after $24 \mathrm{~h})$. Interestingly, the reference WK coat cured for 4-12 days attained markedly lower hardness than the coats modified with NanoBents. Moreover, the final/ highest hardness values for coats with mMMT were observed after 9 days (WK/ZS3, WK/ZR2) and 11 days (WK/ZS1) of their conditioning at room temperature. Probably ammonium salts used as organophilization agents for montmorillonites accelerated the oxidation reaction (i.e., polymerization) of the uralkyd composition and/or siccative adsorption on a modified clay surface occurred.

Gloss and abrasion resistance values for an unmodified WK coat and coats modified with mMMT are presented in Fig. 6. As can be seen, WK/ZS1 sample reached markedly lower gloss (80.4 units) than the reference sample (90.1 units) and the remaining samples with NanoBents (90.0-90.3 units). In the case of abrasion resistance, WK/ZS1 coat as well as the WK/ZR2 sample achieved lower values of that parameter (i.e., 1789 and $1391 \mathrm{~g} / \mu \mathrm{m}$, respectively) in comparison with WK $(1836 \mathrm{~g} / \mu \mathrm{m})$. On the other hand, significantly reduced attrition was observed for a cured uralkyd sample modified with ZS3 $(1927 \mathrm{~g} / \mu \mathrm{m})$. It should be mentioned that WK/ZS3 sample reached markedly lower hardness in comparison with an unmodified coat and systems with either ZS1 or ZR2 (Fig. 5). This coat (WK/ZS3) as well as WK/ZS1 reached significantly higher impact resistance (i.e., $140 \mathrm{~cm}$; Fig. 7) than a reference sample $(125 \mathrm{~cm})$. However, cured uralkyd with ZR2 was characterized only by $115 \mathrm{~cm}$ of that parameter, all coats containing organophilized montmorillonites exhibited higher elasticity (cone no. 5; indentation depth $1.8 \mathrm{~mm}$ ) than a neat sample (no. $6 ; 1.6 \mathrm{~mm}$ ). Probably, that feature was 


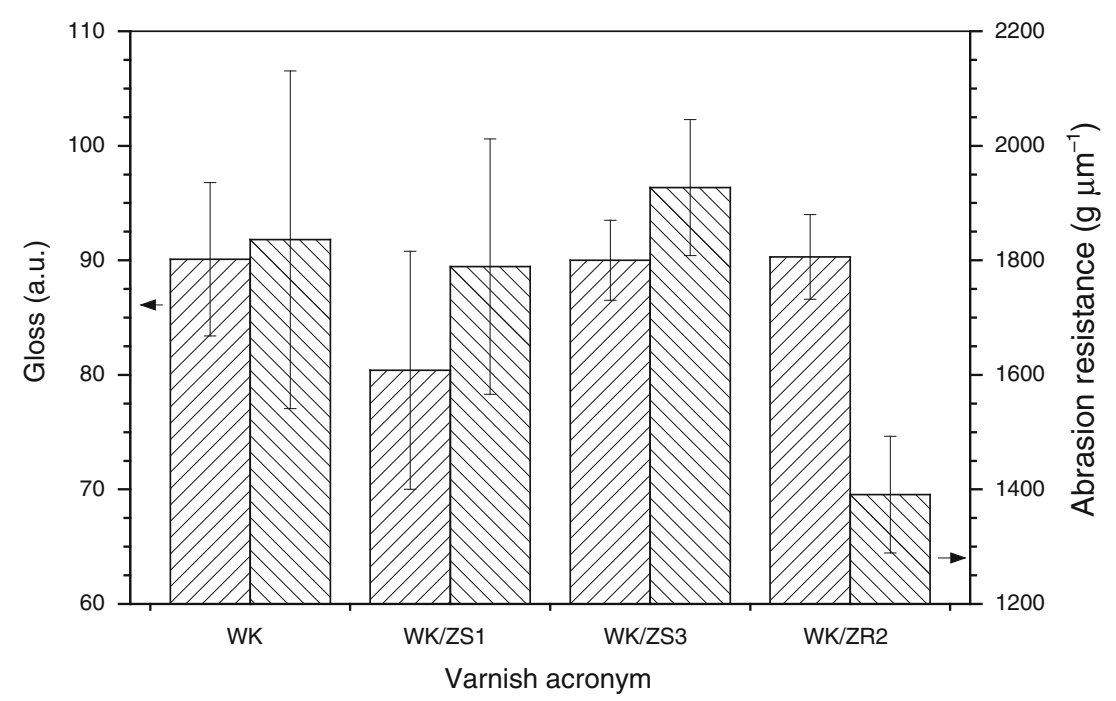

Fig. 6: Gloss and abrasion resistance of uralkyd coats with organophilized montmorillonites

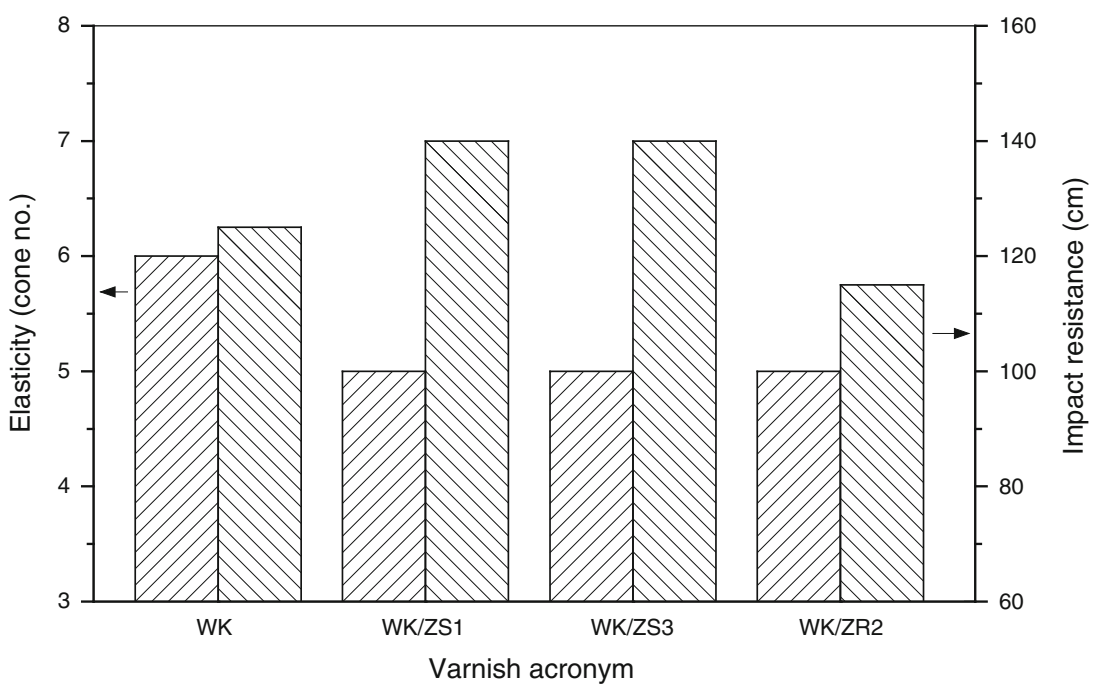

Fig. 7: Elasticity and impact resistance of uralkyd coats with organophilized montmorillonites

affected by hardness of cured coats (i.e., lower hardness for samples with organoclays was registered; Fig. 5), while the impact resistance of $\mathrm{WK} / \mathrm{mMMT}$ samples might depend on the dissipation effectiveness of a nanofiller in an uralkyd matrix (XRD data for WK/ZS1 and WK/ZS3 confirmed complete exfoliation of these montmorillonites in coats). Interestingly, presented mechanical features do not correlate with glass transition temperature values for cured varnishes (Table 1). A neat coat as well as WK/ZS1 and WK/ZR2 exhibited similar $T_{\mathrm{g}}\left(\right.$ ca. $\left.25^{\circ} \mathrm{C}\right)$ while this parameter value for the coat with ZS3 was higher (i.e., $28^{\circ} \mathrm{C}$ ). The mentioned sample reached markedly lower hardness than other systems and similar elasticity in comparison with WK/ZS1 and WK/ZR2. Moreover, WK/ZS3 was based on a nanofiller with higher modifier content (ca. $48 \mathrm{wt} \%$ ) than either WK/ZS1
(42 wt \%) or WK/ZR2 (30 wt \%); thus, a plasticization phenomenon (as a lower $T_{\mathrm{g}}$ value) for this sample could be observed. On the other hand, it should be noted that ZS3 was characterized by the highest gallery space value (i.e., $3.7 \mathrm{~nm}$ ) than other tested organoclays. Although complete exfoliation of ZS3 as well as ZS1 in cured varnishes was noted (Fig. 4) coats with the former mMMT reached significantly better abrasion resistance (Fig. 6). Probably, ZS3 is, in reality, better dissipated in a polymeric matrix than ZS1 and $\mathrm{ZR} 2$ and it affects the $T_{\mathrm{g}}$ value of a cured coat.

Water permeability test results for uralkyd coats (after 1, 3, and 7 days of their immersion in distilled water) are presented in Fig. 8. A coat filled with ZS3 was characterized by slightly lower values of an analyzed parameter after 1 and 3 days of immersion (i.e., 29 and $76 \mathrm{~g} / \mathrm{m}^{2}$, respectively) in comparison with a 


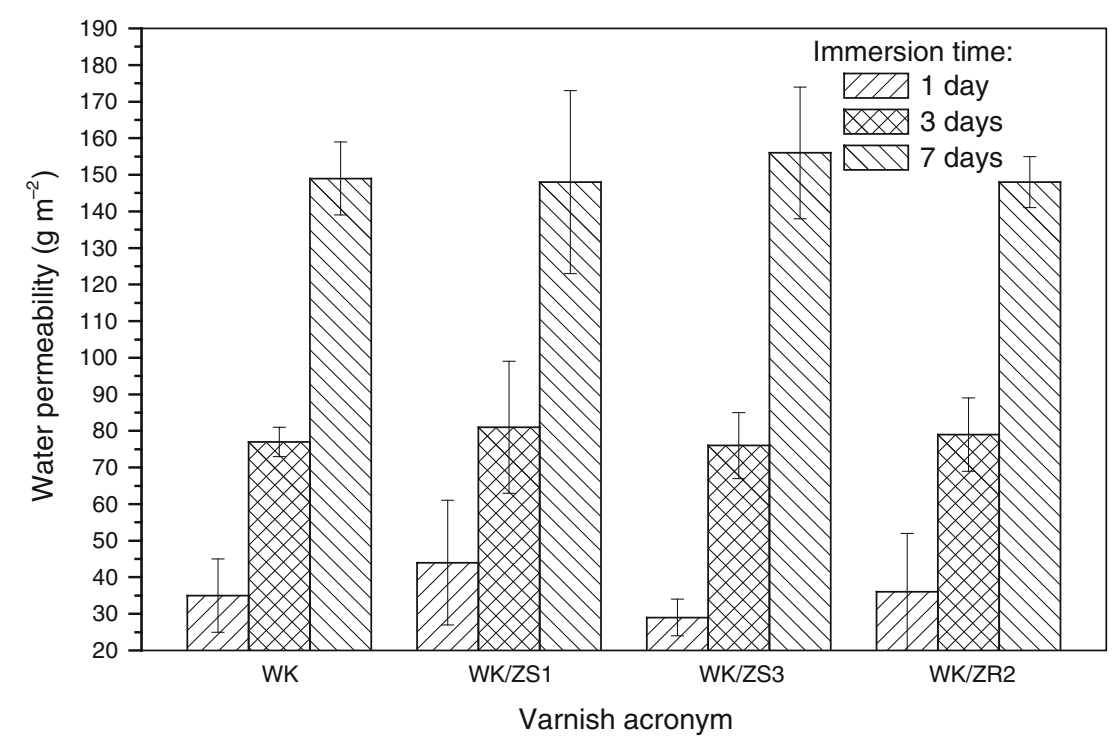

Fig. 8: Water permeability for uralkyd coats with organophilized montmorillonites

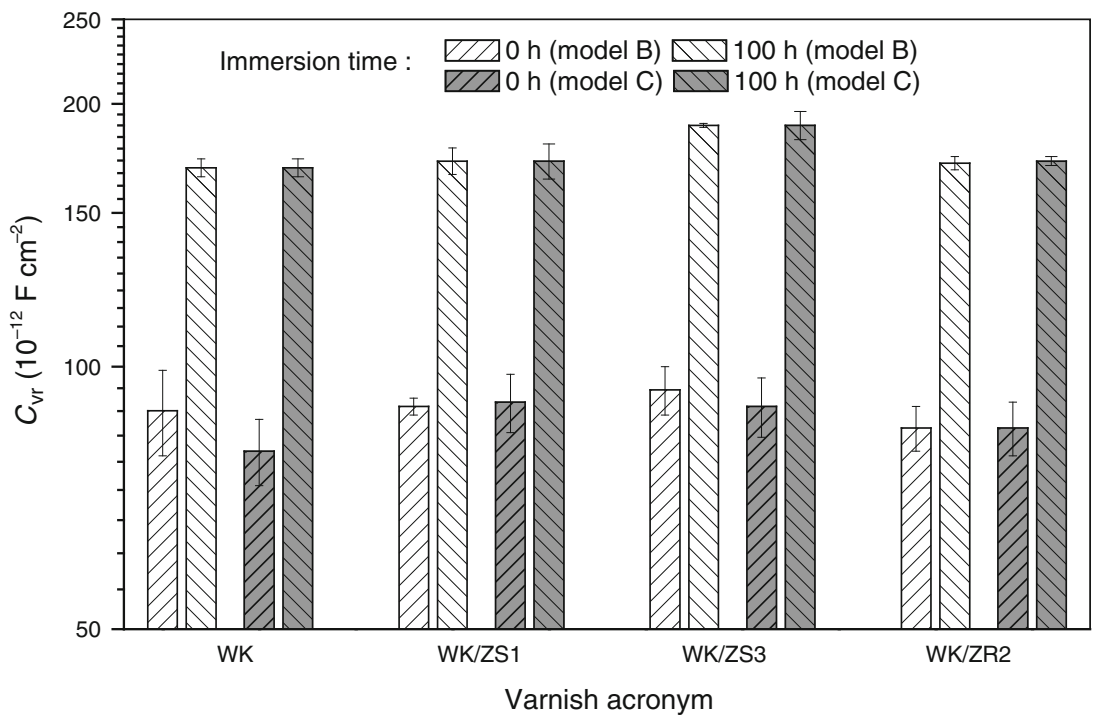

Fig. 9: Relative varnished layer capacitance $\left(C_{\mathrm{vr}}\right)$ variation for samples after vacuum impregnation $(0 \mathrm{~h})$ and additional immersion in an aqueous $\mathrm{NaCl}$ solution $(100 \mathrm{~h})$. The $C_{\mathrm{vr}}$ values were calculated using electric circuit models presented in Fig. 2

reference WK sample (35 and $77 \mathrm{~g} / \mathrm{m}^{2}$ ) as well as WK/ZS1 and WK/ZR2 coats. Nevertheless, water permeability for $\mathrm{WK} / \mathrm{ZS} 3$ after 7 days was markedly higher $\left(156 \mathrm{~g} / \mathrm{m}^{2}\right)$ than the rest of the tested systems. It should be noted that WK, WK/ZS1, and WK/ZR2 reached similar values of a presented parameter at the end of the immersion test $\left(148-149 \mathrm{~g} / \mathrm{m}^{2}\right)$. Water permeability examination results (after 7 days) directly correspond to relative varnished layer capacitance $\left(C_{\mathrm{vr}}\right)$ values calculated on the basis of EIS data (Fig. 9). The exemplary impedance spectra for a wood substrate and WK samples as well as curves fitted on the basis of a standard electric model (Fig. 2b) are presented in Fig. 10. As can be seen WK/ZS3 reached generally higher $C_{\mathrm{vr}}$ values in comparison with either unmodified coats or WK-based coats with ZS1 or ZR2 nanofillers. Although $C_{\mathrm{vr}}$ significantly increased after additional immersion (for $100 \mathrm{~h}$ ) of all impregnated samples in an aqueous $\mathrm{NaCl}$ solution, it should be noted that the above mentioned phenomenon (i.e., the highest $C_{\mathrm{vr}}$ for WK/ZS3) was observed for the samples before and after extra treatment with the saline. Moreover, the relative varnished layer resistance noted for WK/ZS3 (an advanced electric model, Fig. 11) is markedly lower than for other tested samples after vacuum saturation and immersion in an aqueous $\mathrm{NaCl}$ 
solution. The highest $R_{\mathrm{vr}}$ values were calculated for WK/ZS1 (i.e., $6875 \mathrm{M} \Omega . \mathrm{cm}^{2}$ for impregnated specimens and $3720 \mathrm{M} \Omega . \mathrm{cm}^{2}$ after immersion in the saline) while a wooden element coated with an unmodified varnish reached only 5278 and $3330 \mathrm{M} \Omega . \mathrm{cm}^{2}$, respectively. Presented results are probably affected by the type and content of an organic modifier in mMMT; ZS3 is based on the ammonium salt with aliphatic substituents containing several hydroxyl and etheric groups, whereas ZR1 and ZS2 are rather more hydrophobic. In summary, the water permeability (after 7 days of the immersion value; Fig. 8) and $C_{\mathrm{vr}}$ as well as lower $R_{\mathrm{vr}}$ values for WK/ZS3 (in comparison with WK and other WK/nMMT samples) were affected

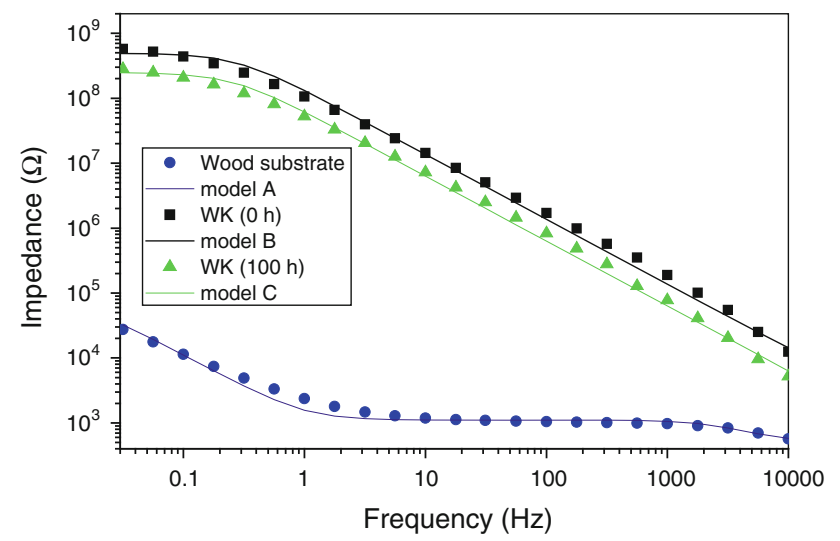

Fig. 10: Registered impedance spectra (symbols) and spectra for electric circuit models presented in Fig. 2 (lines) for unvarnished wood substrate and WK sample after vacuum impregnation $(0 \mathrm{~h})$ as well as after additional immersion in an aqueous $\mathrm{NaCl}$ solution (100 h) by a hydrophilic character and a high ammonium modifier content in ZS3.

Considering the $R_{\mathrm{vr}}$ and $C_{\mathrm{vr}}$ calculated on the basis of either an advanced (Fig. 2b) or simplistic electric model (Fig. 2c), it should be noted that these parameter values are very similar (Fig. 9, Fig. 11). Moreover, the latter model (C) is quite well fitted to the registered EIS spectra (Fig. 10). It means that electric elements of an advanced model, located in a wood substrate and a wood-bolt interface do not significantly affect the final results of varnished layer parameter measurements. Using a reduced electric model for the analysis of $R_{\mathrm{v}}$ and $C_{\mathrm{v}}$ an additional operation (i.e., an electrochemical test of an unvarnished sample) is not needed. Probably that phenomenon is caused by significantly higher electric resistance of a varnished wood layer in comparison with a wood substrate treated with the saline. On the other hand, the electric capacitance, related to the $\mathrm{NaCl}$-free water uptake, is relatively higher for a thin polymeric layer than for wood impregnated with the saline. Additionally, the capacitance element $\left(C_{\mathrm{r}}\right.$, Fig. 2c) may be simultaneously located in a varnished layer and a wood substrate. Although the $R_{\mathrm{v}}$ parameter is more suitable for the barrier properties analysis of varnished wood, the $C_{\mathrm{v}}$ value could also be used for this purpose. Taking into consideration the fact that wood is generally an inhomogeneous material, it must be noted that the deviation of calculated $R_{\mathrm{v}}$ and $C_{\mathrm{v}}$ values is quite low (Figs. 9, 11).

Although better dissipation of ZS3 organoclay in an uralkyd matrix does not improve barrier properties of a cured varnish, WK/ZS3 specimens exhibited similar or improved chemical resistance in relation to the neat WK sample and/or these modified with either ZS1 or ZR2 (Table 2). In the case of blistering resistance (for

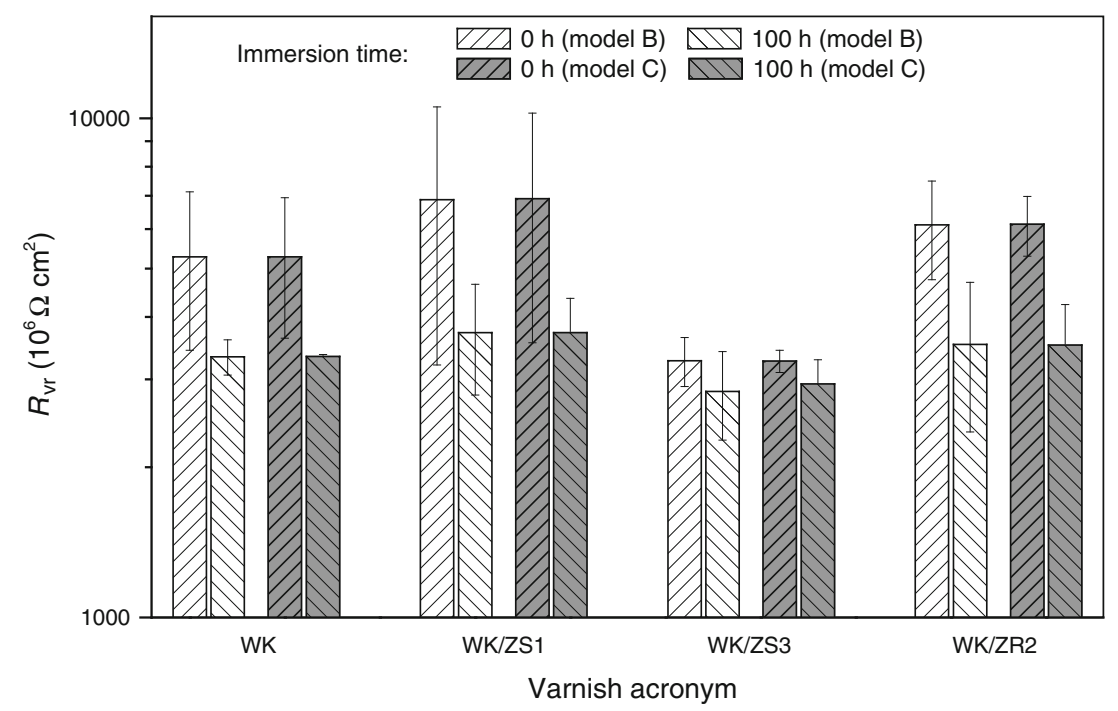

Fig. 11: Relative varnished layer resistance $\left(\boldsymbol{R}_{\mathrm{vr}}\right)$ variation for samples after vacuum impregnation $(0 \mathrm{~h})$ and additional immersion in an aqueous $\mathrm{NaCl}$ solution $(100 \mathrm{~h})$. The $\boldsymbol{R}_{\mathrm{vr}}$ values were calculated using electric circuit models presented in Fig. 2 
Table 2: Chemical resistance of uralkyd coats with organophilized montmorillonites

\begin{tabular}{|c|c|c|c|c|c|}
\hline Chemicals & Defects & WK & WK/ZS1 & WK/ZS3 & WK/ZR2 \\
\hline \multirow[t]{2}{*}{ Acetone } & Discoloration & $0^{\mathrm{b}}$ & 0 & 0 & 0 \\
\hline & Blistering & $3 B^{c}$ & $4 \mathrm{~A}$ & $2 A$ & $2 \mathrm{~A}$ \\
\hline \multirow[t]{2}{*}{ Ammonia $^{a}$} & Discoloration & 3 & 3 & 3 & 2 \\
\hline & Blistering & $2 \mathrm{~A}$ & $3 A$ & $2 \mathrm{~A}$ & $4 \mathrm{~B}$ \\
\hline \multirow[t]{2}{*}{ Acetic acid ${ }^{a}$} & Discoloration & 0 & 0 & 0 & 0 \\
\hline & Blistering & 0 & 0 & 0 & 0 \\
\hline
\end{tabular}

\footnotetext{
10 wt\% aqueous solution

b Discoloration in range from 0 (nonobserved) to 4 (strong discoloration)

${ }^{c}$ Blistering intensity in a range $0-4$ and size of a blister in a range from A (a small blister) to D (a very large blister)
}

acetone), the best results were observed for WK/ZS3 and WK/ZR2 (2A), but after exposition to an aqueous ammonia solution the highest values of the analyzed parameter were registered for WK/ZS3 and WK coats (2A). Although a coat based on ZR2 reached the lowest discoloration value (after treatment with ammonia solution), this sample had unacceptable surface defects (4B). It should be noted that an uralkyd varnish modification with organophilized montmorillonite did not affect chemical resistance of a cured coat exposed to an aqueous solution of the acetic acid.

\section{Conclusions}

Based on the test results of solventborne uralkyd varnishes modified with commercially organophilized montmorillonites and cured on a wooden element, the following conclusions can be drawn:

- Modified montmorillonites significantly affect application, mechanical as well as barrier features of uralkyd varnishes and coats.

- Complete exfoliation of NanoBent ZS1 and NanoBent ZS3 (initial gallery spaces 3.5 and $3.7 \mathrm{~nm}$, respectively) in an uralkyd matrix occurred. In the case of NanoBent ZR2 $(1.9 \mathrm{~nm})$ the intercalation of a polymer into a clay particle was observed.

- A coating composition filled with NanoBent ZS3 exhibits higher viscosity while a varnish with NanoBent ZR2 reaches a lower value of that parameter in comparison with a neat sample (gallery space value of mMMT directly affects viscosity of the varnish).

- Coats modified with NanoBents achieve slightly lower hardness than a reference sample.

- An incorporation of NanoBent ZS3 into an uralkyd coat improves its abrasion resistance $(+5 \%)$, elasticity $(+0.2 \mathrm{~mm}$ of indentation depth), impact resistance $(+12 \%)$, chemical resistance to acetone as well as reduces water permeability after 1 day of immersion in distilled water $(-17 \%)$.

Additionally, the presented electrochemical impedance spectroscopy technique is very convenient and a quick method of barrier properties investigation of organic coats on wooden elements. The data calculated by using a simple electrical model of a coat/wood substrate system correlates well with long-lasting water permeability test results.

Acknowledgments Authors thank Ms. Birte Grätzer (Worlée-Chemie $\mathrm{GmbH}$ ) for supplying the binder for coating compositions. Collaboration of Ms. Alicja Górecka in preparation and characterization of the coats is kindly appreciated.

Open Access This article is distributed under the terms of the Creative Commons Attribution License which permits any use, distribution, and reproduction in any medium, provided the original author(s) and the source are credited.

\section{References}

1. Utracki, LA, "Thermoset Clay-Containing Polymeric Nanocomposites." In: Utracki, LA (ed.) Clay-Containing Polymeric Nanocomposites, pp. 579-609. Rapra Technology, Shawbury, 2004

2. Yao, KJ, Song, M, Houston, DJ, Luo, DZ, "Polymer/ Layered Clay Nanocomposites: 2 Polyurethane Nanocomposites." Polymer, 43 (3) 1017-1020 (2002)

3. Wang, Z, Massam, J, Pinnavaia, TJ, "Epoxy-Clay Nanocomposites." In: Pinnavaia, TJ, Beall, GW (eds.) Polymer-Clay Nanocomposites, pp. 127-149. Wiley, Chichester, 2000

4. Bal, A, Güclü, G, Acar, I, Iyim, TB, "Effects of Urea Formaldehyde Resin to Properties of Alkyd-Melamine Formaldehyde Resins Containing Organo Clay." Prog. Org. Coat., 68 (4) 363-365 (2010)

5. Kowalczyk, K, Spychaj, T, "Protective Epoxy Dispersion Coating Materials Modified A Posteriori with Organophilized Montmorillonites." Surf. Coat. Technol., 204 (5) 635641 (2009)

6. Kowalczyk, K, Spychaj, T, "Epoxy Coatings with Modified Montmorillonites." Prog. Org. Coat., 62 (4) 425-429 (2008)

7. Nobel, ML, Picken, SJ, Mendes, E, "Waterborne Nanocomposite Resins for Automotive Coating Application." Prog. Org. Coat., 58 (2-3) 96-104 (2007) 
8. Ahmadi, B, Kassiriha, M, Khodabakhshi, K, Mafi, E, "Effect of Nanolayered Silicates on Automotive Polyurethane Refinish Clearcoat." Prog. Org. Coat., 60 (2) 99-104 (2007)

9. Uhl, F, Davuluri, S, Wong, S, Webster, CD, "Organically Modified Montmorillonites in UV Curable Urethane Acrylate Films." Polymer, 45 (18) 6175-6187 (2004)

10. Ray, S, Okamoto, M, "Polymer/Layered Silicate Nanocomposites: A Review from Preparation to Processing." Prog. Polym. Sci., 28 (11) 1539-1641 (2003)

11. Scarfato, P, Di Maio, L, Fariello, M, Russo, P, Incarnato, L, "Preparation and Evaluation of Polymer/Clay Nanocompos- ite Surface Treatments for Concrete Durability Enhancement." Cem. Concr. Compos., 34 (3) 297-305 (2012)

12. Leung, C, Zhu, H, Kim, J, Woo, R, "Use of Polymer/ Organoclay Nanocomposite Surface Treatment as Water/Ion Barrier for Concrete." J. Mater. Civ. Eng., 20 (7) 484-492 (2008)

13. Landry, V, Blanchet, P, Riedl, B, "Mechanical and Optical Properties of Clay-Based Nanocomposites Coatings for Wood Flooring." Prog. Org. Coat., 67 (4) 381-388 (2010)

14. Landry, V, Riedl, B, Blanchet, P, "Nanoclay Dispersion Effects on UV Coatings Curing." Prog. Org. Coat., 62 (4) 400-408 (2008) 